\title{
Somebody Google a Doctor! Urgent Health Information Seeking Habits of Young Adults
}

\author{
Jason Anthony Cain ${ }^{1^{*}}$ \\ (iD) 0000-0003-3091-4754
}

\section{Cory Armstrong ${ }^{2}$}

(iD) 0000-0003-4730-9665

\section{Jue Hou ${ }^{2}$}

(iD) 0000-0002-8441-8468

${ }^{1}$ School of Journalism and New Media, University of Mississippi, USA

2 Department of Journalism and Creative Media, University of Alabama, USA

* Corresponding author: jacain@olemiss.edu

Citation: Cain, J. A., Armstrong, C., \& Hou, T. (2020). Somebody Google a Doctor! Urgent Health Information Seeking Habits of Young Adults. Online Journal of Communication and Media Technologies, 10(2), e202006. https://doi.org/10.29333/ojcmt/7853

\section{ARTICLE INFO}

Received: 18 Dec 2019

Accepted: 19 Feb 2020

\section{ABSTRACT}

Introduction: While much scholarship has been done on health information-seeking habits, comparatively little has been done on these habits among young adults.

Objective: The primary objective of this study was to determine to which media young adults turn during an urgent health crisis, which factors correspond to their choice, and if informationseeking corresponded to visiting a health professional.

Method: A survey method was used, sampling students from two large universities.

Results: Credibility was the most consistent factor in predicting respondent media choice for an urgent health matter. Whether respondents were socially conservative or liberal affected media choice, as did perceptions of online and traditional media credibility. Searching for health information online corresponded to more frequently visiting health professionals.

Conclusion: This study supports that young adults turn to a variety of media sources, traditional and online, during health crisis and that this information-seeking does correspond to visiting health professionals after.

Keywords: health communication, mediated sources, information-seeking behaviors, information sufficiency

\section{INTRODUCTION}

One morning an 18-year old female college freshman noticed a 1-inch wide puffy red growth on her breast while she was getting dressed for class. Her first action was to log onto her computer and ask Google for more information about her condition. Visiting a site such as WebMD, she was asked questions about tenderness and texture of the growth, along with directions for self-breast examination. After roughly 30 minutes of internet use, she believed she had a benign cyst. She promptly contacted a health provider and scheduled an appointment, explaining her "self-diagnosis."

In the contemporary era, the case above is no longer unique since more and more Americans are turning online for researching health information. In fact, more than 70 percent of adults between ages 18-29 go online to seek information about a specific medical condition or ailment (Fox \& Duggan, 2013). Traditional websites, social media, and apps continue to grow as important constituents of the American health information diet.

Copyright $(\mathbf{2 0 2 0}$ by authors; licensee OJCMT. This article is an open access article distributed under the terms and conditions of the Creative Commons Attribution License (http://creativecommons.org/licenses/by/4.0/). 
Previous scholarship on this area of study has several notable gaps. First, even though literature on information-seeking behavior is relatively abundant in general and has a long history (e.g. Bennett\& Mandell, 1969; Howard \& Sheth, 1969), very few studies specifically focused on such information-seeking behavior among young adults (e.g. Syn \& Kim, 2016). Second, as a widely utilized modern information-seeking tool, the internet is rapidly evolving since established in the 1990s (Chaffee \& Metzger, 2001; Brubaker, 2008). Thus, further research targeting how young adults-often the most technologically adept in general-seek information on health issues is important for understanding their behaviors.

The present study looks in particular at the young adults and their motivations for accessing health information online in time of an immediate health crisis. Given the reliance of young adults on technology, it follows that self-diagnosis is likely before heading to a health provider. Contributing to previous related literature, this study aims to provide a holistic picture of young adults' information-seeking behavior in the contemporary era. What tools do young adults employ in learning about health-related issues? And how do they determine the credibility of that information?

Findings from this study will generally help public health officials and other researchers in better understanding how the public engages with health information online. More specifically, it will add to a specific understanding where young adults turn when a health matter is urgent and why they may have chosen those sources.

\section{LITERATURE REVIEW}

\section{Information Seeking}

Information seeking studies reach back to at least the mid-20th century and initially featured most prominently in marketing research. These studies made use of learning theory as a point of departure in investigating information seeking (Bennett \& Mandell, 1969; Howard \& Sheth, 1969). These studies break information seeking into three areas, "extensive problem solving behavior, limited problem solving behavior, and routinized response behavior" (Bennett \& Mandell, 1969, p. 430-431). Since advertising dollars are finite, a great deal of scholarship on information seeking prior to the popular adoption of the internet focused on effective pull strategies through marketing methods of the time and traditional media such as television and print (Bennett \& Mandell, 1969; Howard \& Sheth, 1969; Kiel \& Layton, 1981).

All of this is not to say that information seeking behavior is only the province of marketing and advertising. From the outset, the internet posed a challenge to the traditional understanding of mass communication (Chaffee \& Metzger, 2001), and developments in the mid-2000s only muddied these waters (Brubaker, 2008), precisely because of a user's ability to personalize their media mix and choose from such a wide variety of information sources. Researchers recognized the importance of information-seeking behavior as the internet diffused ever more broadly across the population, even as they realized that there was a lack of scholarship into information seeking behavior through computer-mediated communication. "This vast array of digital resources allows users to create their own personalized media environments rather than relying on the one traditionally provided by mainstream media" (Ramirez, Walther, Brugoon, \& Sunnafrank, 2002, p.213). Though information-seeking behavior in relation to risk (Eastin, Kahlor, Liang, \& Ghannam, 2015); politics (Smith \& Gustfson, 2017; Brubaker, 2008; Weeks \& Southwell, 2008), and/or health (Willoughby \& Myrick, 2016; Rains, 2008) has been the subject of past research, understanding the process fully remains a moving target.

\section{Health Information Seeking Online}

In 2001, Cline and Haynes cited studies noting that by 1998, nearly half of US-based internet users had used the technology for health research. By 2013, Pew research found that over a third of American adults accessed specific health information online and nearly half reported that this information influenced them to see a health professional (Fox \& Duggan, 2013). Additionally, over the last decade, social media have grown into a primary role in internet communication to the point that nearly $70 \%$ of adults in the US use these platforms (Pew, 2018). Health information seeking on social media has increased along with the popularity of these media over the same time (Prestin, Vieux, \& Chou, 2015). 
In their initial study, Cline and Haynes (2001) found women and African-Americans were more likely to turn to the internet for health-related information, In the case of African-Americans, the authors speculated that this may be due to economics and barriers to "traditional health information sources" (Cline \& Haynes, 2001 , p. 674). The authors also noted previous studies that indicated women were more likely to use the internet for seeking health information and that the majority of health information seekers were over 40 . Additional studies (Ball-Rokeach \& Wilkins, 2008), have also noted that the Hispanic population varies in health information seeking habits, with socioeconomic standing and country of origin having an association with their level of information seeking. In contrast with previous studies, research by McGloin et al. (2016) suggests that gender may not be a significant factor in predicting health information seeking behavior. It seems then, that more support for the notion that the internet's constant evolution creates a need for continually reexamining previous assumptions.

A decade later, Percheski and Hargittai (2011) examined health information seeking habits of first year university students, and some trends remained the same. Among college students, women were still more likely to use the Internet for health information seeking while the predictive power of race on seeking health information online, particularly among black participants, was not supported.

Other research has noted a difference between heterosexual populations and other sexual orientations in the health information seeking process. A 2014 report by the CDC (Ward, Dahlhamer, Galinsky, \& Joestl, 2014) noted that minority sexual orientations supported a difference between health issues and access to health care. For example, those who identified as gay or bisexual were more likely to have been tested for HIV, and women who identified as gay, lesbian, or bisexual were less likely to have consistent health care provider. This study also noted the difficulty in obtaining a robust sample in surveys due to the small percentage of sexual minorities within the greater populations and recommended further study of this population in all areas of health research.

Specific to health-information seeking, Bond, Hefner, and Drogos (2009) found that the internet was a primary source of information for researching the coming-out process, with young adults reporting the highest frequency of use. Magee, Bigelow, DeHaan, and Mustanski (2011) found that young adults identifying as LGBT tended to shy away from searching for sexual health information online either due to perceived irrelevance, incredulity of the source, or concerns over stigmatization. Nonetheless, seeking sexual health information was widely spread in the sample when either the topic had a particular relevance or felt the health matter was urgent.

While the previous studies mentioned explored health information seeking on the internet, no particular emphasis was placed on social media. Social media can at times seem a bit of a hazy term, but to synthesize explanations, social media are platforms, sites, or apps on which users can create a profile, connect The Pew Research Center's (2018) longitudinal data indicates that among adults, social media use rose from 8 percent in 2005 to 50 percent by May 2010. Currently it hovers around 70 percent (Pew 2018). Even in 2010, social media use among adults 18-29 was nearly 75 percent, the sharpest growth occurring between 2005 and 2012 (Pew 2018). Since 2012, social media penetration among young adults has remained between 84 and 90 percent, indicating both quite a bit of growth since the Percheski and Hargittai study (2011) and a stable level of saturation.

Preliminary research conducted by Vaterlaus, Patten, Roche, and Young (2015) supported that social media presented a particularly powerful new avenue through which to connect with young adults, noting in particular the motivational power user-generated content demonstrating either positive health outcomes or a user level of efficacy in living a healthy lifestyle. Research into health information activities on social media remain scant, but some studies do exist. Syn \& Kim (2016) investigated motivations for passive information seeking on Facebook, as well as actively posting about health topics. The researchers found little motivation to actively post content about health information, with students preferring to passively consume content. Additionally, they found that information source preference was associated with how personal the health issue was to the information seeker.

One last note must be made on the role credibility plays. Research has supported that perceived credibility does play a part in influencing information source selection (Carpenter, DeVellis, Hogan, Fisher, DeVellis, \& Jordan, 2011; Rains \& Karmikel, 2009). Carpenter et al. (2011) found in studying information seeking in regard 
to medication that respondents felt positively about internet credibility, though physicians still ranked highest. However, it was also found that gender and other factors could impact views on credibility. Phau and Tinkham (2016) found social media presented an information resource for persons investigating health issues surrounding obesity, particularly when the information was being presented by someone who had personal experience with the same health issues, which increased how credible they found the information.

Given the sparseness of literature on young adult health information seeking habits, the rapid changes to the internet since becoming part of life in the mid-1990s, and the sometimes-conflicting nature of past research, the present study is somewhat exploratory in nature. Additionally, part of our focus is what the addition of a time component may do in shaping media use and choice among young adults. Studies have noted time-sensitivity to influence information-seeking behavior in various ways (e.g. Ybarra \& Suman, 2006; Houston \& Allison, 2002; Chaudhry et al., 2006). In this case, health-information seeking habits during an urgent health crisis remain a relatively open area of information seeking study, and the present study aims to provide some useful insight as to where and why young adults turn where they do when time is of the essence.

\section{Media Literacy and Audience Reception of Media Messages}

For the present study, it is believed there should be some differences present between informationseeking and consumption habits between students majoring in fields related to the study of mediated messages and students outside of those fields. This is not to say that the study is primarily interested in differences between majors but the effect media literacy has on source credibility and source selection. Past research supports this expectation for increased media literacy among students in fields relating to mediated communication (McCall, 1987; Phang \& Schaefer, 2009; Ken \& Taylor, 2005; Rogers \& Chaffee, 1983). Additionally, the industry of mediated communication in the contemporary era have a growing demand for multi-skilled practitioners (Wenger, Owens, \& Cain, 2018; Rhodes \& Roessner, 2009), resulting in the elevating emphasis on technical skills within communication education (Carpenter, 2009). Phang and Schaefer (2009) practical-oriented teaching is more impactful in terms of increasing media literacy.

Despite this assumption in education, in the practical field, support for such notion is scarce. Yet, differences between communication students and students with other majors were discovered in terms of consuming media messages in some studies. For instance, in a study focused on young adults' perception about news, Armstrong, McAdams and Cain (2015) found out that news about consumer product and governmental issues were more appealing to communication students, while other students were more interested in sports, crime and weather news. Non-communication students were also more likely to seek and share opinion-laden media messages. As we are concerned with what predicts why a young adult turns to what media they do in times of an urgent health crisis, media literacy seems an important dimension to investigate.

\section{Hypotheses and Research Questions}

Past research has indicated that for general health information seeking, credibility has played a role in media choice selection (Phua \& Tinkham, Carpenter et al., 2011; Rains \& Karmikel, 2009). Additionally, past research has also indicated media literacy plays a role in perceptions of credibility and selection of information sources (Armstrong, McAdams, \& Cain, 2015; Phang \& Schaefer, 2009). As such, the following hypotheses are proposed:

$\mathrm{H} 1 \mathrm{a}$ - In examining use of health-related information, participants from backgrounds where more media literacy might be expected will vary from those without in terms of perceived source credibility.

$\mathrm{H} 1 \mathrm{~b}$ - In examining use of health-related information, participants from backgrounds where more media literacy might be expected will vary from those without in terms of source use.

$\mathrm{H} 2 \mathrm{a}$ - In examining use of health-related information, source credibility will be positively correlate with source use.

$\mathrm{H} 2 \mathrm{~b}$ - The same positive correlation between credibility and use will exist whether a respondent is a communication major or a non-communication major.

H3 - Recent internet use in researching health matters will correlate with respondents visiting health professionals after searching for health-information online. 
Past literature has noted several groups are more likely to turn online to access health care information; however, the online environment is rapidly changing, particularly with the growing domination of social media segment of the internet. Additionally, while past studies have examined how young adults use a particular platform (Syn \& Kim, 2016, Vaterlaus et al., 2015) few studies exist that look across social media, the Internet at large, and more traditional media use for health information seeking among this group, particular when looking for information in regard to urgent health matters. In light of past research that notes reasons for health information seeking online are not the same across the whole population, as well as the ever-changing nature of internet communication, two research questions are being asked:

RQ1 - Which factors predict a young adult choosing a particular type of media for seeking health information in an urgent health crisis?

RQ2 - Which factors predict a young adult having used the internet in the past seven days in researching an urgent health matter.

\section{METHODS}

To examine these hypotheses and research questions, an online survey was conducted from September 15-October 15, 2017 at two large southeastern universities. Participant recruitment came from two student research pools, along with recruitment from a large general education undergraduate class and an undergraduate media writing course. The total $n$ was 569. Nearly 30 cases were excluded due to the respondent's failure to complete the entire survey. The final dataset included a 75 percent female participant sample, 84 percent who chose white as their race, and 42 percent who indicated they were mass communications majors, compared with 38 percent who indicated they were business majors. These variables were recoded into dummy variables for use in a later regression analysis where for gender, 24 percent were male, and 76 percent were women and other. For race, 85 percent were white, and 15 percent were other. For major, 43 percent were mass communications majors, and 57 percent were other.

For year in school, students were given the options of freshmen to graduate student. Most respondents were juniors (40\%). with sophomores (29\%) and freshmen (21\%) following behind. Respondents were also asked about sexual orientation using categories also used by the Centers for Disease Control and Prevention as a guide (CDC, 2017). In the end, the sample was 95\% heterosexual, so the options of gay, lesbian, bisexual, and other were combined into one composite "other" category. Participants were to self-report their views on a 1 (conservative) to 7 (liberal) scale for social issues $(M=3.69, S D=1.72)$ and economic issues $(M=3.12, S D=$ 1.51). These four variables in addition to the demographic dummy variables for gender, race, and major comprise the set of control variables used in a later regression analysis.

\section{Independent Variables}

Based on prior research (Armstrong, McAdams, \& Cain, 2015; Phang \& Schaefer, 2009), whether a student was a mass communication or other major was used as an independent variable for a series of t-tests to determine if there are any differences in attitude toward the credibility and use of various media outlets based on media literacy.

A series of exploratory factor analyses (EFA) were run to reduce three batteries asked to assess respondent views of credibility by source, interest in health matters, and how frequently respondents sought out specific health matters. These batteries were informed by previous studies using similar scales in general and healthrelated information seeking studies. Each EFA used a varimax rotation. Additionally, in each analysis, coefficients below 40 were suppressed.

For the EFA reducing the source credibility items, statements from Anker, Reinhart, and Feeley (2011) were adapted for use as items. The initial test revealed that two statements, the statement in regard to finding health professionals a respondent most often visits and the statement in regard to television programming other than news being credible, cross loaded into two components. These were removed from analysis as a result. A. KMO value of .81 was obtained as well as statistical significance $(p<.01)$ in Bartlett's Test of Sphericity, suggesting the factorability of the correlation matrix (Bartlett, 1954; Kaiser, 1970). The EFA revealed two components, traditional media sources $\left(R^{2}=.30\right)$ and internet sources $\left(R^{2}=.21\right)$ with summed square loadings of 2.37 and 1.69. The EFA was used to collapse these statements into a traditional media variable (summed 
Table 1. Health Information Source Credibility Items

\begin{tabular}{ccc}
\hline Statement & Mean & SD \\
\hline The doctor or health professionals I most regularly see & 6.53 & 1.042 \\
\hline Internet Websites (Excluding social media and blogs) & 4.13 \\
\hline Social Media (Facebook, Twitter, Snapchat, Pinterest, YouTube, etc.) & 2.98 & 1.42 \\
\hline Internet Blogs & 2.81 & 3.49 \\
\hline Print Newspapers & 3.84 & 3.61 \\
\hline Print Magazines & 4.41 \\
\hline Health Segments on Television News & 3.19 \\
\hline Television other than News & 1.52 \\
\hline Print or Electronic Books & 4.09 \\
\hline
\end{tabular}

scale items yield $M=15.41, S D=5.24$ ) and an internet sources variable (summed scale items yield $M=9.87, S D$ = 3.49).

When reducing the scale measuring how frequently respondents searched for various health topics by a EFA method (Table 1), a KMO value of .85 was obtained as well as statistical significance $(p<.01)$ in Bartlett's Test of Sphericity, suggesting the factorability of the correlation matrix (Bartlett, 1954; Kaiser, 1970). The EFA revealed two components, sexual-health/prevention $\left(R^{2}=.37\right)$ and nutrition/wellness $\left(R^{2}=.19\right)$ with sum of squared loadings of 3.37 and 1.69 respectively. Frequency of looking for preventative information loaded into both factors, so the cutoff loading was adjusted to .42, eliminating further cross-loading. The EFA was used to collapse these statements into sexual-health/prevention variable (summed scale items yield $M=8.23, S D=$ 3.24) and nutrition/wellness variable (summed scale items yield $M=17.79, S D=7.81$ ).

The last scale to be reduced by a EFA method was the scale measuring importance of consuming health information. A KMO value of .88 was obtained as well as statistical significance $(p<.01)$ in Bartlett's Test of Sphericity, suggesting the factorability of the correlation matrix (Kaiser, 1970; Bartlett, 1954). A single component $\left(S S=4.32, R^{2}=.54\right.$ ) was revealed by this analysis, and the EFA was used to collapse these statements a single health interest variable (summed scale items yield $M=36.86, S D=10.35$ ).

\section{Dependent Variables}

Questions asking if a respondent has ever visited a doctor after accessing health information online, if they have used the internet in the last seven days to learn about a health issue, and if they had ever used the internet in searching for health information were asked. These variables were created to capture how many respondents have recently used the internet for health questions and which respondents have visited a health professional after seeking information online. Each of these variables had additional answers for "don't know" and/or "prefer not to answer." When used in H3 and RQ2, only answers that were a clear "yes" or "no" were included, excluding $n=38$ for the question about doctors and $n=36$ for use in the last seven days. All respondents chose either "yes" or "no" when asked if they had ever used the internet in searching for health information. Due to the overall sample size, this selection was done in order to represent only respondents that were either willing to share or could clearly remember whether they had participated in these behaviors or not rather than having to introduce an element of speculation when investigating these variables.

The Likert -items from the batteries on health information source credibility and frequency of use were used as the DVs in a series of T-test to determine if there was a significant difference in attitude between mass communication majors and non-majors. These items were also adapted from Anker et al. (2011). Additionally, these items comprised the variables in a Pearson product-moment correlation to determine if there was a relationship between attitude toward credibility and frequency of use.

The final two DVs were created from an EFA of the scale measuring health-information source use in the last 30 days In the initial test, the items "internet blogs" and "television besides news" cross-loaded into more than one factor. The cutoff factor was adjusted to .5, eliminating the blog item and loading television into only one factor. The final EFA resulted in a KMO value of .84 was obtained as well as statistical significance $(p<.01)$ in Bartlett's Test of Sphericity, suggesting the factorability of the correlation matrix (Kaiser, 1970; Bartlett, 1954). Two components were revealed, one relating to internet media use (SS loading $=2.91, R^{2}=.36$ ) and the other traditional media use $\left(S S=1.63, R^{2}=.2\right)$. The EFA was used to collapse these statements an internet 
Table 2. Frequency of Source Use in Last 30 Days for Urgent Health Matters

\begin{tabular}{ccc}
\hline Statement & Mean & SD \\
\hline Internet Websites (Excluding social media and blogs) & 1.36 & .88 \\
\hline Social Media (Facebook, Twitter, Snapchat, Pinterest, YouTube, etc.) & 1.22 & .1 .16 \\
\hline Internet Blogs & .55 & .24 \\
\hline Print Newspaper & .39 & .62 \\
\hline Print Magazines & .49 & .70 \\
\hline Health Segments on Television News & .65 \\
\hline Television other than News & .41 \\
\hline Print or Electronic Books & .73 \\
\hline
\end{tabular}

media use variable (summed scale items yield $M=2.48, S D=1.74$ ) and a traditional media use variable (summed scale items yield $M=2.25, S D=3.06$.

\section{RESULTS}

For $\mathrm{H} 1 \mathrm{a}$, a series of independent samples T-tests were run for the measure of perceived credibility on each of the nine health information sources presented (Table 1). The results demonstrate limited support for $\mathrm{H} 1 \mathrm{a}$, with significant credibility scores differing in only two of the nine items. Mass communication majors viewed health professionals as significantly more credible on average $(M=6.53, S D=1.04)$ than non-majors $[M=6.31$, $S D=1.36 ; t(567)=2.07, p=.04]$. Print magazines were also seen as more credible on average by mass communications majors $(M=3.61, S D=1.52)$ vs. non-majors $[M=3.27, S D=1.45 ; t(567)=2.73, p<.01]$.

To test $\mathrm{H} 1 \mathrm{~b}$, a second series of independent samples T-tests were run on the reported frequency of in the last 30 days for the 8 sources listed as separate items in the question (Table 2). No significant differences were found in frequency of use of these sources between majors and non-majors, leaving H1b unsupported.

To test $\mathrm{H} 2 \mathrm{a}$, a series of Pearson product moment tests for correlation were run between the statements in Tables 1 and 2 to see if attitudes toward credibility correlated with frequency of use on the same source in the last 30 days. The results of these tests are in Table 3. As predicted, higher credibility scores correlated to more use, supporting $\mathrm{H} 2 \mathrm{a}$.

For $\mathrm{H} 2 \mathrm{~b}$, first cases where the respondent reported being a mass communication majors were selected and the same Pearson product moment test for correlation was conducted across the same variables as in $\mathrm{H} 2 \mathrm{a}$. Next, cases containing non-majors were selected, and the test was repeated, the results of which are in Table 3. For major, a similar correlation pattern to what was seen when all cases were included was found, with higher credibility scores being correlated to more frequent use. For non-majors, this pattern was largely the same with the exception of "Print or Electronic Books" ( $r=.08 n=326, p=.13)$. Considering this was the only difference between the two groups, support for $\mathrm{H} 2 \mathrm{~b}$ was minimal. 
Table 3. Pearson Product Moment Tests for Correlation between Credibility and Use of Health Information Sources in the last 20 Day

\begin{tabular}{|c|c|c|c|}
\hline Variable & Group & r for sample & r by group \\
\hline \multirow{3}{*}{$\begin{array}{l}\text { Internet Websites (Excluding social media } \\
\text { and blogs) }\end{array}$} & Overall & $.24 * \star$ & \\
\hline & Mass Comm Majors & & $.21 * \star$ \\
\hline & Non-Majors & & $.26 * \star$ \\
\hline \multirow{3}{*}{$\begin{array}{l}\text { Social Media (Facebook, Twitter, Snapchat, } \\
\text { Pinterest, YouTube, etc.) }\end{array}$} & Overall & $.41 * \star$ & \\
\hline & Mass Comm Majors & & $.36 * \star$ \\
\hline & Non-Majors & & $.46 * \star$ \\
\hline \multirow{3}{*}{ Internet Blogs } & Overall & $.44^{\star \star}$ & \\
\hline & Mass Comm Majors & & $.37 * \star$ \\
\hline & Non-Majors & & $.49 * \star$ \\
\hline \multirow{3}{*}{ Print Newspaper } & Overall & $.17^{\star \star}$ & \\
\hline & Mass Comm Majors & & $.17^{\star \star}$ \\
\hline & Non-Majors & & $.18 * \star$ \\
\hline \multirow{3}{*}{ Print Magazines } & Overall & $.28 * \star$ & \\
\hline & Mass Comm Majors & & $.32 * \star$ \\
\hline & Non-Majors & & $.26 * \star$ \\
\hline \multirow{3}{*}{ Health Segments on Television News } & Overall & $.25 * \star$ & \\
\hline & Mass Comm Majors & & $.28 * \star$ \\
\hline & Non-Majors & & $.24 * \star$ \\
\hline \multirow{3}{*}{ Television other than News } & Overall & $.35 * \star$ & \\
\hline & Mass Comm Majors & & $.39 * \star$ \\
\hline & Non-Majors & & $.32 * \star$ \\
\hline \multirow{3}{*}{ Print or Electronic Books } & Overall & $.19 * \star$ & \\
\hline & Mass Comm Majors & & $.32 * \star$ \\
\hline & Non-Majors & & .08 \\
\hline
\end{tabular}

$\mathrm{N}=569$

$\star *=\mathrm{p}<.01$

$\star=p<.05$

For H3, a chi-square test for independence was conducted between variables asking respondents if they had ever used the internet for finding health-related information and if they had ever visited a health professional after searching for such information. The test supported a relationship between searching for such information and visiting health professionals afterward, $\chi^{2}(2, N=518)=14.04, p<.01$. Respondents that answered they had used the internet for searching for health information were also more likely to report having visited a health professional after accessing such information, supporting H3.

In order to answer RQ1, two hierarchical linear regressions were conducted in order to examine predictors of health information seeking in the last 30 days. There were two DVs as the EFA discussed produced an internet media component and a traditional media component, which were used as two variables using the respective media use in each component. For the traditional media use variable (Table 4), the first block included control variables for gender, race, class in college, major, and sexual orientation and accounted for 9 percent of the variance. Two statistically significant results were found in this block: gender, which suggests that males were more likely than women to have used traditional media in the last 30 days $(\beta=-.25, p<.05)$ and sexual orientation $(\beta=1.20, p<.01)$, with respondents with orientations other than heterosexual being more like to have used traditional media.

Block 2 added political views on social matters and political views of fiscal matters and accounted for 1 percent of the variance. However, views on social issues produced a significant negative association $(\beta=-.08$, $p<.05$ ), supporting that respondents with conservative social views were more likely to use traditional media. Block 3 introduced variables on general interest in health information and how often respondents looked for specific health topics and explained 12 percent of the variance. In this block, searching for wellness/nutrition topics $(\beta=-.12, p<.01)$ demonstrated a negative association. Frequently searching for information on sexual and preventative health $(\beta=-.31, p<.01)$ produced positive associations. Block 4 introduced the traditional and internet media credibility variables, explaining 7 percent of the variance. Both traditional media credibility $(\beta=.17, p<.01)$ and internet media credibility $(\beta=.16, p<.01)$ produced significant positive associations. 
Table 4. Hierarchical Linear Regression of Key Predictors of Information Seeking in Last 30 days For Urgent Health Matter on Traditional Media

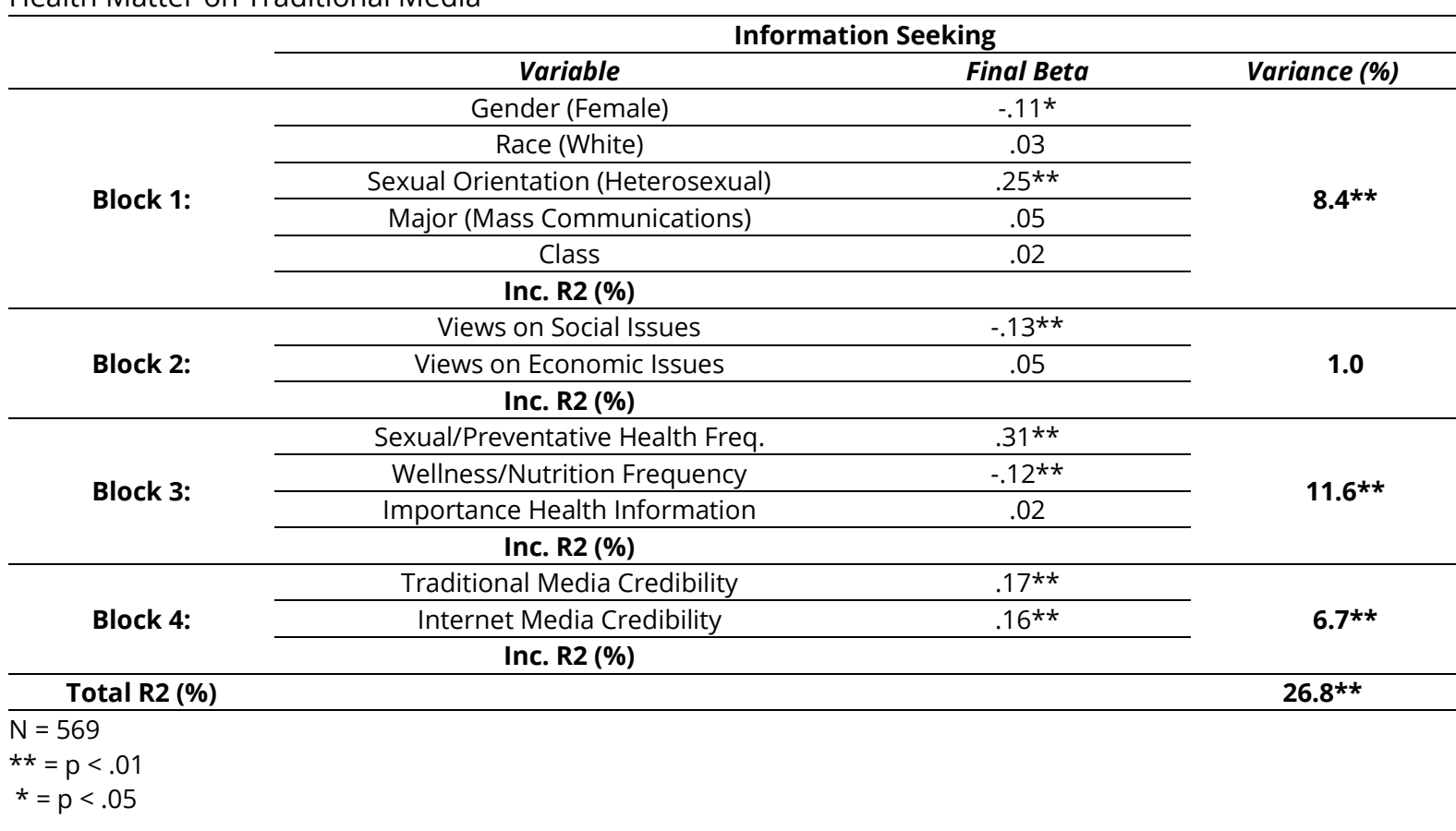

Table 5. Hierarchical Linear Regression of Key Predictors of Information Seeking in Las 30 days For Urgent Health Matter on Internet Media

\begin{tabular}{|c|c|c|c|}
\hline & \multicolumn{3}{|c|}{ Information Seeking } \\
\hline & Variable & Final Beta & Variance (\%) \\
\hline \multirow{6}{*}{ Block 1: } & Gender (Female) & -.05 & \multirow{6}{*}{1.1} \\
\hline & Race (White) & -.07 & \\
\hline & Sexual Orientation (Heterosexual) & .03 & \\
\hline & Major (Mass Communications) & -.05 & \\
\hline & Class & .02 & \\
\hline & Inc. R2 (\%) & & \\
\hline \multirow{3}{*}{ Block 2: } & Views on Social Issues & -.01 & \multirow{3}{*}{0.7} \\
\hline & Views on Economic Issues & $.05^{*}$ & \\
\hline & Inc. R2 (\%) & & \\
\hline \multirow{4}{*}{ Block 3: } & Sexual/Preventative Health Freq. & $.15^{\star \star}$ & \multirow{4}{*}{$11.0 * *$} \\
\hline & Wellness/Nutrition Frequency & .06 & \\
\hline & Importance Health Information & $.13^{*}$ & \\
\hline & Inc. R2 (\%) & & \\
\hline \multirow{3}{*}{ Block 4: } & Traditional Media Credibility & -.00 & \multirow{3}{*}{$5.6 * *$} \\
\hline & Internet Media Credibility & $.25 * \star$ & \\
\hline & Inc. R2 (\%) & & \\
\hline Total R2 (\%) & & & $18.5^{* *}$ \\
\hline $\begin{array}{l}=569 \\
=p<.01 \\
=p<.05\end{array}$ & & & \\
\hline
\end{tabular}

A similar hierarchical linear regression targeting the second variable, use of internet information sources in the last 30 days in searching for urgent health information, was conducted (Table 5). The first block included control variables for gender, race, class in college, major, and sexual orientation and accounted for 1 percent of the variance and no significant predictors. Block 2 added political views on social matters and political views of fiscal matters and accounted for 1 percent of the variance. Economic issues produced a significant positive association $(\beta=.05, p<.05)$, supporting that respondents with more liberal economic views were more likely to have turned to internet sources in the last 30 days. Block 3 again introduced variables on general interest in health information and how often respondents looked for specific health topics and explained 11 percent of the variance. In the case of internet sources, frequently searching for information on sexual and 
Table 6. Hierarchical Linear Regression of Key Predictors of Information Seeking in Last 7 days For Urgent Health Matter on Internet Media

\begin{tabular}{|c|c|c|c|}
\hline & \multicolumn{3}{|c|}{ Information Seeking } \\
\hline & Variable & Final Beta & Variance (\%) \\
\hline \multirow{6}{*}{ Block 1: } & Gender (Female) & .03 & \multirow{6}{*}{1.1} \\
\hline & Race (White) & -.04 & \\
\hline & Sexual Orientation (Heterosexual) & .00 & \\
\hline & Major (Mass Communications) & -.03 & \\
\hline & Class & .02 & \\
\hline & Inc. R2 (\%) & & \\
\hline \multirow{3}{*}{ Block 2: } & Views on Social Issues & .01 & \multirow{3}{*}{0.0} \\
\hline & Views on Economic Issues & .08 & \\
\hline & Inc. R2 (\%) & & \\
\hline \multirow{4}{*}{ Block 3: } & Sexual/Preventative Health Freq. & -.05 & \multirow{4}{*}{$6.8 * *$} \\
\hline & Wellness/Nutrition Frequency & .04 & \\
\hline & Importance Health Information & $.19 * \star$ & \\
\hline & Inc. R2 (\%) & & \\
\hline \multirow{3}{*}{ Block 4: } & Traditional Media Credibility & -.05 & \multirow{3}{*}{$4.9 * *$} \\
\hline & Internet Media Credibility & $.25 * \star$ & \\
\hline & Inc. R2 (\%) & & \\
\hline Total R2 (\%) & & & $12.8 * *$ \\
\hline $\begin{array}{l}N=569 \\
*=p<.01 \\
*=p<.05\end{array}$ & & & \\
\hline
\end{tabular}

preventative health $(\beta=.15, p<.01)$ and importance placed on health information $(\beta=.13, p<.05)$ produced a positive association. Block 4 introduced the traditional and internet media credibility variables, explaining 6 percent of the variance. Internet media credibility $(\beta=.25, p<.01)$ produced significant positive associations.

To answer RQ2, a hierarchical regression was performed on the variable asking if respondents had used the internet in the last seven days find health-related information. The same blocks were used in the previous regression models, yielding the results found in Table 6 . An overall interest in health information $(\beta=.19, p<$ $.01)$ and more favorable opinions in regard to the credibility of information found on the internet $(\beta=.25, p<$ .01) were the only two significant variables found in the final model, demonstrating that as scores on these two variables increased so did the likelihood that a respondent had used the internet in the last week to research an urgent health matter.

\section{DISCUSSION}

The first two hypotheses tested whether or not media literacy would have an effect on health information seeking behavior. Past research has argued that students majoring in communications-related fields tended to exhibit more media literacy (Armstrong, McAdams, \& Cain, 2015; Phang \& Schaefer, 2009), so a student's major was used as a way to predict media literacy. To that end, findings support that communication majors find health professionals and print magazines somewhat more credible than non-majors, and that attitudes toward the credibility of Books, both print and electronic, did not correlate to frequency of use for non-majors. Even these slight differences disappeared when modeling which factors seem to predict when young adults turning to either traditional media sources or the internet for health information. Our battery of information sources collapsed neatly into internet and traditional media variables, and interestingly, there were some differences in which characteristics predicted use, supporting that even among young adults, there is perhaps and audience for traditional media that could be targeted. Finally, as expected, credibility does correlate to use in every instance, both generally and between majors, with the exception of books noted above.

In a media environment that essentially assumes internet media is synonymous with young adults, it is interesting to see which factors predict using traditional media. Support for gender playing a role in predicting use, particularly in regard to more use by males, presents a somewhat unexpected break from some pervious scholarship (Ball-Rokeach \& Wilkins, 2008; McGloin et al., 2016; Percheski \& Hargittai, 2011). 
$\mathrm{H} 3$ predicted that respondents who used the internet for seeking health information were more likely to have visited a doctor or health professional afterward, and this prediction was supported, lending further evidence to past studies that young adults (Percheski \& Hargittai, 2011), and indeed people in general (Fox \& Duggan, 2013), who search for information online seem more likely to follow up on health concerns with a doctor. Furthermore, RQ2 revealed that respondents who found internet sources credible and felt consuming health information was important were more likely to have searched for health-related information in the past week. Taking these results together, there is reason to believe that efforts to make consuming health information more relevant to young adults, as well as providing sources they trust online, will result in more of this group searching for information online. Likewise, there continues to be support that this behavior does result in an increase of visiting health professional to follow up on what a young adult as found online about his or her health concern.

In the case of internet media use in the last 30 days, none of the control variables proved significant. A developing but possibly unfounded assumption about youth in the contemporary era is that social media is the only way to communicate with this group. To a certain extent, findings of the current study argue against that assumption. Economically conservative respondents had a higher likelihood of using traditional media sources as part of their information-seeking habits, where more socially liberal respondents demonstrated an increased likelihood of using the Internet. For those interested in sexual and preventative health topics, traditional media use also increased.

As the battery of questions on source credibility also neatly loaded into internet and traditional media categories, it was possible to see if an overall belief in credibility in one area predicted a corresponding frequency of use. Unsurprisingly, higher credibility scores in one area predicted a higher frequency of use in the corresponding media type, supporting past research (Carpenter, DeVellis, Hogan, Fisher, DeVellis, \& Jordan, 2011; Rains \& Karmikel, 2009). However, both internet and traditional media credibility predicted an increased frequency of use of traditional media in the last 30 days, suggesting that perhaps respondents who use traditional media find more credibility in general of mediated messages, whether they appear in print, broadcast, a webpage, or social media. It's interesting to see that among young adults, credulity of traditional media didn't associate with an increase in its use as it did in the case of internet media. Whether this is a product of access to these media, simply a preference toward internet media, perhaps a product of immediacy in information seeking online, or some other factor cannot be answered by these data, but it presents an interesting question to explore in future research.

In regard to differences between majors and where that may come into play when investigating urgent health information sources, the only area in which communication majors differed from other majors was in the case of medical professional credibility. While this test was significant, it should be noted that on a sevenpoint scale, majors ( $M=6.53$ ) and non-majors $(M=6.31$ ) gave medical professionals very high marks on average in regard to credibility. Mass communication majors also scored print magazines significantly more credible on average than non-majors.

While these findings provide some evidence of the differences expected based on previous scholarship (Phang \& Schaefer 2009; Kent \& Taylor, 2005), in the case of this sample, these differences seemed limited. If one accepts the argument that individuals with a mass communication major/degree are generally more media literate than others, then this finding debunks that assumption. Perhaps, media literacy is being taught in elementary and secondary schools, which gives all students a well-rounded look at media literacy. However, this study seems overall to argue that differences in internet use and source credibility were not related to field of study.

The present study does have some limitations. While efforts were made to create a wide representation of areas of study at each university for the sample, the sample population skewed heavily female, and there is a notable underrepresentation of minority races. Race remains an important area for future study as past research indicates there are differences to be found (Ball-Rokeach \& Wilkins, 2008; Percheski \& Hargitai, 2011)). These populations also tend to be at greater health risk (Ward et al., 2014; Cline \& Haynes, 2001), so better understanding about where they search for information is essential in better serving them. In the case of race, the present study found no significance, but that could be a product of under representation. In the case of sexual orientation, evidence of a difference was discovered, but it must be taken with a grain of salt 
due to the low number of respondents. Given past scholarship (Magee et al., 2011; Bond et al., 2009), the current findings, while preliminary in nature, underscore that health information seeking and the LGBTQ population remain an area that needs further exploration.

The present study does ultimately provide insight into the evolving world of health information seeking habits, specifically such habits among young adults seeking information regarding urgent health matters. It supports the notion that credibility continues to play an important role in considering information sources, and also supports the need for approaching mass media holistically - continuing to study how to better communicate through the diverse media landscape that exists online while not forgetting that traditional media remain an important part of a young adult's media diet. Even though a clear distinction emerges between online media and traditional media, there is some evidence that they are each still seen to serve a purpose in health information seeking habits and both present opportunities in supporting young adults' efforts to serve their health needs. Maybe most importantly, from a practical stand point, it lends support that providing young adults with sources they trust and reinforcing the importance of a proactive approach to learning about health leads to more information seeking and ultimately more in-person contact with health professionals.

\section{REFERENCES}

Anker, A. E., Reinhart, A. M., \& Feeley, T. H. (2011). Health information seeking: a review of measures and methods. Patient education and counseling, 82(3), 346-354. https://doi.org/10.1016/j.pec.2010.12.008

Armstrong, C. L., McAdams, M. J., \& Cain, J. (2015). What is news? Audiences may have their own ideas. Atlantic Journal of Communication, 23(2), 81-98. https://doi.org/10.1080/15456870.2015.1013102

Ball-Rokeach, S. J., \& Wilkin, H. A. (2009). Ethnic differences in health information-seeking behavior: Methodological and applied issues. Communication Research Reports, 26(1), 22-29. https://doi.org/10.1080/08824090802636983

Bartlett, M. S. (1954). A note of the multiplying factors for various Chi-squares approximations. Journal of Royal Statistical Society, 16 (series B), 296-298. https://doi.org/10.1111/j.2517-6161.1954.tb00174.x

Bennett, P. D., \& Mandell, R. M. (1969). Prepurchase information seeking behavior of new car purchasers: The learning hypothesis. Journal of Marketing Research, 430-433. https://doi.org/10.1177/ 002224376900600405

Bond, B. J., Hefner, V., \& Drogos, K. L. (2009). Information-seeking practices during the sexual development of lesbian, gay, and bisexual individuals: The influence and effects of coming out in a mediated environment. Sexuality \& Culture, 13(1), 32-50. https://doi.org/10.1007/s12119-008-9041-y

Boyd, D. M., \& Ellison, N. B. (2008). Social Network Sites: Definition, History, and Scholarship. Journal of Computer-Mediated Communication, 13, 210-230. https://doi.org/10.1111/j.1083-6101.2007.00393.x

Brubaker, J. (2008). The freedom to choose a personal agenda: Removing our reliance on the media agenda. American Communication Journal, 10(3), 1-1. Retrieved from https://www.ac-journal.org/

Carpenter, D. M., DeVellis, R. F., Hogan, S. L., Fisher, E. B., DeVellis, B. M., \& Jordan, J. M. (2011). Use and perceived credibility of medication information sources for patients with a rare illness: Differences by gender. Journal of Health Communication, 16(6), 629-642. https://doi.org/10.1080/10810730.2011.551995

CDC. (2017). 2017 National Youth Risk Behavior Survey. Retrieved from https://www.cdc.gov/healthyyouth/data/yrbs/pdf/2017/2017_yrbs_national_hs_questionnaire.pdf

Chaffee, S. H., \& Metzger, M. J. (2001). The end of mass communication? Mass Communication \& Society, 4(4), 365-379. https://doi.org/10.1207/S15327825MCS0404_3

Chaudhry, B., Wang, J., Wu, S., Maglione, M., Mojica, W., Roth, E., ... \& Shekelle, P. G. (2006). Systematic review: impact of health information technology on quality, efficiency, and costs of medical care. Annals of Internal Medicine, 144(10), 742-752. https://doi.org/10.7326/0003-4819-144-10-200605160-00125

Cline, R. J., \& Haynes, K. M. (2001). Consumer health information seeking on the Internet: The state of the art. Health Education Research, 16(6), 671-692. https://doi.org/10.1093/her/16.6.671

Eastin, M. S., Kahlor, L. A., Liang, M. C., \& Abi Ghannam, N. (2015). Information-seeking as a precaution behavior: Exploring the role of decision-making stages. Human Communication Research, 41(4), 603-621. https://doi.org/10.1111/hcre.12062 
Fox, S., \& Duggan, M. (2013). Health online 2013. Pew Research Center. Retrieved from http://www.pewinternet.org/2013/01/15/health-online-2013/

Houston, T. K., \& Allison, J. J. (2002). Users of Internet health information: differences by health status. Journal of medical Internet research, 4(2). https://doi.org/10.2196/jmir.4.2.e7

Kaiser, H. F. (1970). A second generation little jiffy. Psychometrika, 35(4), 401-415. https://doi.org/10.1007/BF02291817

Kent, M. L., \& Taylor, M. (2005). Taking your public relations experience from the boardroom into the classroom. Public Relations Quarterly, 50(1), 13-18.

Kiel, G. C., \& Layton, R. A. (1981). Dimensions of consumer information seeking behavior. Journal of Marketing Research, 18(2), 233-239. https://doi.org/10.1177/002224378101800210

Magee, J. C., Bigelow, L., DeHaan, S., \& Mustanski, B. S. (2012). Sexual health information seeking online: A mixed-methods study among lesbian, gay, bisexual, and transgender young people. Health Education \& Behavior, 39(3), 276-289. https://doi.org/10.1177/1090198111401384

McCall, J. M. (1987). Liberal arts focus provides training for media careers. The Journalism Educator, 42(2), 17 21. https://doi.org/10.1177/107769588704200206

McGloin, R., Richards, K., \& Embacher, K. (2016). Examining the potential gender gap in online health information-seeking behaviors among digital natives. Communication Research Reports, 33(4), 370-375. https://doi.org/10.1080/08824096.2016.1224169

Obar, J. A., \& Wildman, S. S. (2015). Social media definition and the governance challenge: An introduction to the special issue. Telecommunications Policy, 39(9), 745-750. https://doi.org/10.1016/j.telpol.2015.07.014

Percheski, C., \& Hargittai, E. (2011). Health information-seeking in the digital age. Journal of American College Health, 59(5), 379-386. https://doi.org/10.1080/07448481.2010.513406

Pew Research Center. (2018). Internet/broadband fact sheet. Pew Research Center. Retrieved from http://www.pewinternet.org/fact-sheet/internet-broadband/

Phang, A., \& Schaefer, D. J. (2009). Is ignorance bliss? Assessing Singaporean media literacy awareness in the era of globalization. Journalism \& Mass Communication Educator, 64(2), 156-172. https://doi.org/10.1177/107769580906400203

Phua, J., \& Tinkham, S. (2016). Authenticity in obesity public service announcements: Influence of spokesperson type, viewer weight, and source credibility on diet, exercise, information seeking, and electronic word-of-mouth intentions. Journal of Health Communication, 21(3), 337-345. https://doi.org/10.1080/10810730.2015.1080326

Prestin, A., Vieux, S. N., \& Chou, W. Y. S. (2015). Is online health activity alive and well or flatlining? Findings from 10 years of the Health Information National Trends Survey. Journal of Health Communication, 20(7), 790-798. https://doi.org/10.1080/10810730.2015.1018590

Rains, S. A., \& Karmikel, C. D. (2009). Health information-seeking and perceptions of website credibility: Examining web-use orientation, message characteristics, and structural features of websites. Computers in Human Behavior, 25(2), 544-553. https://doi.org/10.1016/j.chb.2008.11.005

Ramirez, A., Walther, J. B., Burgoon, J. K., \& Sunnafrank, M. (2002). Information-seeking strategies, uncertainty, and computer-mediated communication. Human communication research, 28(2), 213-228. https://doi.org/10.1111/j.1468-2958.2002.tb00804.x

Rhodes, L., \& Roessner, A. (2009). Teaching magazine publishing through experiential learning. Journalism \& Mass Communication Educator, 63(4), 304. https://doi.org/10.1177/107769580806300403

Rogers, E. M., \& Chaffee, S. H. (1983). Communication as an academic discipline: A dialogue. Journal of Communication, 33(3), 18-30. https://doi.org/10.1111/j.1460-2466.1983.tb02402.x

Smith, B. K., \& Gustafson, A. (2017). Using Wikipedia to predict election outcomes: Online behavior as a predictor of voting. Public Opinion Quarterly, 81(3), 714-735. https://doi.org/10.1093/poq/nfx007

Syn, S. Y., \& Kim, S. U. (2016). College students' health information activities on Facebook: Investigating the impacts of health topic sensitivity, information sources, and demographics. Journal of Health Communication, 21(7), 743-754. https://doi.org/10.1080/10810730.2016.1157652

Vaterlaus, J. M., Patten, E. V., Roche, C., \& Young, J. A. (2015). \# Gettinghealthy: The perceived influence of social media on young adult health behaviors. Computers in Human Behavior, 45, 151-157. https://doi.org/10.1016/j.chb.2014.12.013 
Ward, B. W., Dahlhamer, J. M., Galinsky, A. M., \& Joestl, S. S. (2014). Sexual orientation and health among US adults. National Health Interview Survey, 2013. Retrieved from https://stacks.cdc.gov/view/cdc/24087

Weeks, B., \& Southwell, B. (2010). The symbiosis of news coverage and aggregate online search behavior: Obama, rumors, and presidential politics. Mass Communication and Society, 13(4), 341-360. https://doi.org/10.1080/15205430903470532

Wenger, D. H., Owens, L. C., \& Cain, J. (2017). Help Wanted: Realigning Journalism Education to Meet the Needs of Top US News Companies. Journalism \& Mass Communication Educator, 71(1), 18-36. https://doi.org/10.1177/1077695817745464

Willoughby, J. F., \& Myrick, J. G. (2016). Does context matter? Examining PRISM as a guiding framework for context-specific health risk information seeking among young adults. Journal of Health Communication, 21(6), 696-704. https://doi.org/10.1080/10810730.2016.1153764

Ybarra, M., \& Suman, M. (2006). Reasons, assessments and actions taken: sex and age differences in uses of Internet health information. Health education research, 23(3), 512-521. https://doi.org/10.1093/her/cyl062

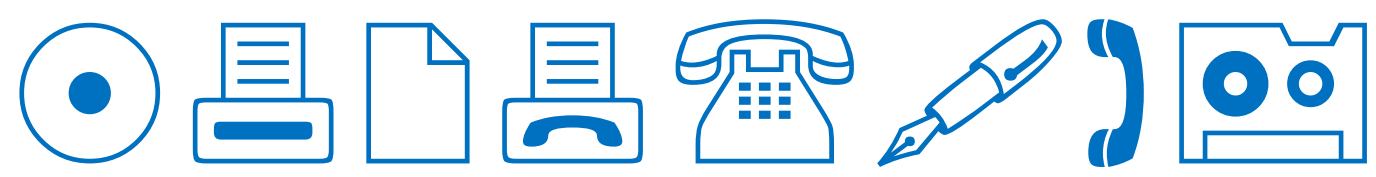

